CAPSULE COMMENTARIES

\title{
Capsule Commentary on Long et al., Why Aren't More Primary Care Residents Going Into Primary Care? A Qualitative Study
}

\author{
Judith Lauren Chasin, M.D. \\ Family Physician, Urgent Care Medicine, St. Luke's Health System, Boise, ID, USA.
}

J Gen Intern Med 31(12): 1503

DOI: $10.1007 / \mathrm{s} 11606-016-3881-1$

(c) Society of General Internal Medicine 2016

$\mathrm{T}$ he study by Long et al. ${ }^{1}$ investigates the important issue of the increasing shortage of primary care physicians in the U.S. The investigators conducted a multi-site qualitative study, interviewing a total of 24 second- and third-year residents from three different internal medicine residency programs. They found four themes that reduced the likelihood of going into primary care: 1) resident perception of primary care careers, 2) difficulty navigating the social and medical needs of patients, 3) lack of mentorship, and 4) structural features of training programs that encouraged going into specialty care. The authors make a number of suggestions that might improve the residents' training experience, including broadening overall outpatient exposure, and improving mentorship and perceptions of primary care. While training and mentorship clearly play a role in every physician's career path, this focus represents only a small part of what is, in fact, an impending crisis in healthcare with multiple contributing factors. ${ }^{1}$ A brief discussion of some of these issues, ranging from cost of education to the impact of legislative changes, would provide readers with deeper context and added perspective, as well as adding validity to the study. ${ }^{2}$ Moreover, while the sites were purposefully selected, the specific sites are not given in the manuscript; through personal communication with the authors, however, it was found that the sites were all in the Northeast, a significant limitation. In addition, no information was given about the practice patterns or location of the primary care physicians that the residents were being exposed to. It is possible that the problems reported by the residents' mentors may be less in settings with different practice models (such as the patient-centered medical home [PCMH] or that of the Veterans Health Administration [VA]). ${ }^{3}$ Another limitation is the myopic focus on internal medicine residents; it would have been useful to incorporate family medicine residents, as the American Academy of Family Physicians (AAFP) has played a large role in population health management, incorporating the PCMH, and in discussions on the overarching changes in the field of primary care medicine. ${ }^{4}$

Corresponding Author: Judith Lauren Chasin, M.D.; Family Physician, Urgent Care Medicine, St. Luke's Health System, Boise, ID, USA (e-mail: lauren.chasin@gmail.com).

\section{Compliance with Ethical Standards:}

Conflict of Interest: The author has no conflicts of interest with this article.

\section{REFERENCES}

1. Long T, Chaiyachati K, Bosu O, Sircar S, Richards B, Garg M, et al. Why aren't more primary care residents going into primary care? A qualitative study. J Gen Intern Med. 2016. doi:10.1007/s11606-016-3825-9.

2. Castrucci B. Primary Care and Public Health: A Partnership to Change America's Health. Huffington Post. Jan 26 2015. http://www. huffingtonpost.com/brian-castrucci/primary-care-public-healt_b_ 6516564.html. Accessed 1 Sept 2016.

3. American Academy of Physicians. Testimony to the House Subcommittee on Labor, Health and Human Services, \& Education, and Related Agencies Appropriations FY 2016. April 27, 2015. http://www.aafp.org/dam/AAFP/ documents/advocacy/workforce/title-vii/TS-House-Appropriations042715.pdf. Accessed 1 Sept 2016.

4. Robert Graham Center. Workforce Projections. http://www.graham-center. org/rgc/publications-reports/browse-by-topic/workforce.html. Accessed 1 Sept 2016.

Published online October 11, 2016 